\title{
Safety and effectiveness of the Low Profile Visualized Intraluminal Support (LVIS and LVIS Jr) devices in the endovascular treatment of intracranial aneurysms: results of the TRAIL multicenter observational study
}

\author{
Christina losif, ${ }^{1}$ Michel Piotin, ${ }^{2}$ Suzana Saleme, ${ }_{1}^{1}$ Xavier Barreau, ${ }_{1}{ }^{\text {Jacques Sedat }}{ }_{1}^{4}$ \\ Yves Chau, ${ }^{4}$ Nader Sourour, ${ }^{5}$ Mohamed Aggour, ${ }^{6}$ Herve Brunel, ${ }^{7}$ Alain Bonafe, ${ }^{8}$ \\ Paolo Machi, ${ }^{8}$ Carlos Riquelme, ${ }_{1}^{8}$ Vincent Costalat, ${ }^{8}$ Laurent Pierot, ${ }^{9}$ Raphael Blanc, ${ }_{1}^{2}$ \\ Charbel Mounayer, ${ }^{1}$ on behalf of the TRAIL Investigators
}

- Additional material is published online only. To view please visit the journal online (http://dx.doi.org/10.1136/ neurintsurg-2017-013375).

For numbered affiliations see end of article.

Correspondence to Dr Christina losif,

Departments of Interventional Neuroradiology, CHU-Limoges Dupuytren University Hospital, Limoges 87042, France; christina.iosif@gmail.com

Received 2 August 2017 Revised 30 October 2017 Accepted 2 November 2017 Published Online First 24 November 2017

Check for updates

To cite: losif C, Piotin M

Saleme $S$, et al.

J Neurolntervent Surg

2018:10:679-685.

\section{ABSTRACT}

Background and purpose To evaluate the safety and effectiveness of the low-profile braided intracranial stents called the Low Profile Visualized Intraluminal Support (LVIS) devices for stent-assisted coil embolization of wide-necked intracranial aneurysms.

Materials and methods This was a prospective, multicenter, observational study of unruptured and ruptured intracranial aneurysms treated with the LVIS devices. Imaging and clinical data were independently analyzed respectively by CoreLab and Clinical Event Committee. Primary endpoints were clinical safety, effectiveness, and angiographic stability of the results at 6 and 18 months.

Results Ten centers participated in the study; 102 patients were included and 90 patients (42.2\% men, $57.8 \%$ women) were eventually analyzed, among which $27(30.0 \%)$ had multiple aneurysms. Twentythree $(25.6 \%)$ were ruptured aneurysms, four of which $(4.4 \%)$ were treated in the acute phase. One aneurysm was treated per patient; 92 LVIS and LVIS Jr devices were placed overall. The total aneurysm occlusion rate was $91.0 \%$ on immediate post-procedure angiograms, which remained unchanged at 6-month follow-up and was $92.4 \%$ at 18 -month follow-up. One patient (1.1\%) underwent retreatment between 6 and 18 months of follow-up. A modified Rankin score of 0 was documented for most cases immediately after the procedure (86.7\%) and at 6-month (86.8\%) and 18-month (83.3\%) followup. The overall permanent morbidity rate at 18 months was $5.6 \%$ and the overall rate of events with sequelae related to the stent was $2.2 \%$. The 18 -month procedurerelated mortality rate was $3.3 \%$. No patient was deemed to require retreatment at 18-month follow-up.

Conclusion The LVIS/LVIS Jr endovascular devices are safe and effective in the treatment of ruptured and unruptured intracranial aneurysms, with acceptable complication rates, very high immediate total occlusion rates, and stable angiographic results.

\section{INTRODUCTION}

Endovascular coiling of ruptured intracranial aneurysms is an established first-line treatment which has been shown to prevent aneurysm re-rupture and to improve clinical outcome. ${ }^{1}$ Recent data showed an equally significant benefit of endovascular treatment for unruptured intracranial aneurysms. ${ }^{2}$ Nevertheless, technical issues such as aneurysm neck width and anatomic morphology expressed as the dome-to-neck and aspect ratios are factors that may increase technical difficulty for some cases. ${ }^{3}$

Stent-assisted coiling provides better and stable anatomic results in complex wide-necked intracranial aneurysms than coiling or remodelling. ${ }^{4}$ The mechanism of action seems to be multifactorial, providing a scaffold for coiling and subsequent endothelialization $^{5}$ and, at the same time, acting hemodynamically by slightly diverting blood flow away from the aneurysm sac. ${ }^{6}$ The presence of stent struts on the parent artery promotes rapid aneurysm endothelialization of the neck area and also protects the potentially fragile artery around the aneurysm neck by neointimal coverage of the parent artery. ${ }^{7}$

The objective of this study was to evaluate the safety and effectiveness of the LVIS device for the treatment of ruptured or unruptured wide-necked and anatomically complex intracranial aneurysms, for which a simple endovascular treatment or balloon remodeling was considered challenging or impossible.

\section{METHODS}

\section{Study design}

The TRAIL study is a prospective, multicenter, non-comparative, observational study. Evaluation criteria included anatomic stability of the treatment at 6 and 18 months, retreatment rates, and clinical outcome.

\section{Ethical standards}

The study received required national regulatory authorization: approval from the Consultative Committee of Information Processing in Healthcare Research programme, and the National Commission for Data Processing and Freedom. All included patients were fully informed of the study objectives by the investigators and by a patient information sheet. Patients agreed with anonymized data collection in the study frame. 


\section{Sample size determination}

In the absence of reliable epidemiological data on wide-necked intracranial aneurysms, the target population size was calculated using the National Medical Act registry for the year 2010, according to which 3400 patients were supported for intracranial aneurysm obliteration by the transcutaneous arterial route. Among these, 10\% were deemed suitable for the combined use of stent and coils. The target population of the study was thus estimated at 340 patients.

Because of foreseeable recruitment difficulties due to the small size of the target population, the bilateral CI threshold was increased to $\pm 10 \%$. The recruitment of 75 patients was calculated by the appropriate statistical formula as being the minimum necessary to achieve the desired precision objective (10\% accuracy). However, given the unpredictable number of patients who are usually lost to follow-up, the sample size was increased to 90 patients in order to ensure a minimum of 75 cases with complete follow-up. An inclusion period of 24 months was intended in order to obtain this number.

\section{Population analysis}

The included patients, for whom an endovascular procedure with an LVIS device was scheduled, constituted the intent-totreat (ITT) population. Patients included but not treated, as well as procedure failures, were kept in the analysis population. Patients implanted with a device other than the LVIS device were described separately and were excluded from the ITT population.

\section{Safety and effectiveness evaluation criteria}

Clinical evaluation of the patients was performed with the modified Rankin Scale (mRS). Performance of the devices was evaluated by imaging follow-up at 6 and 18 months, revised independently by the CoreLab investigators.

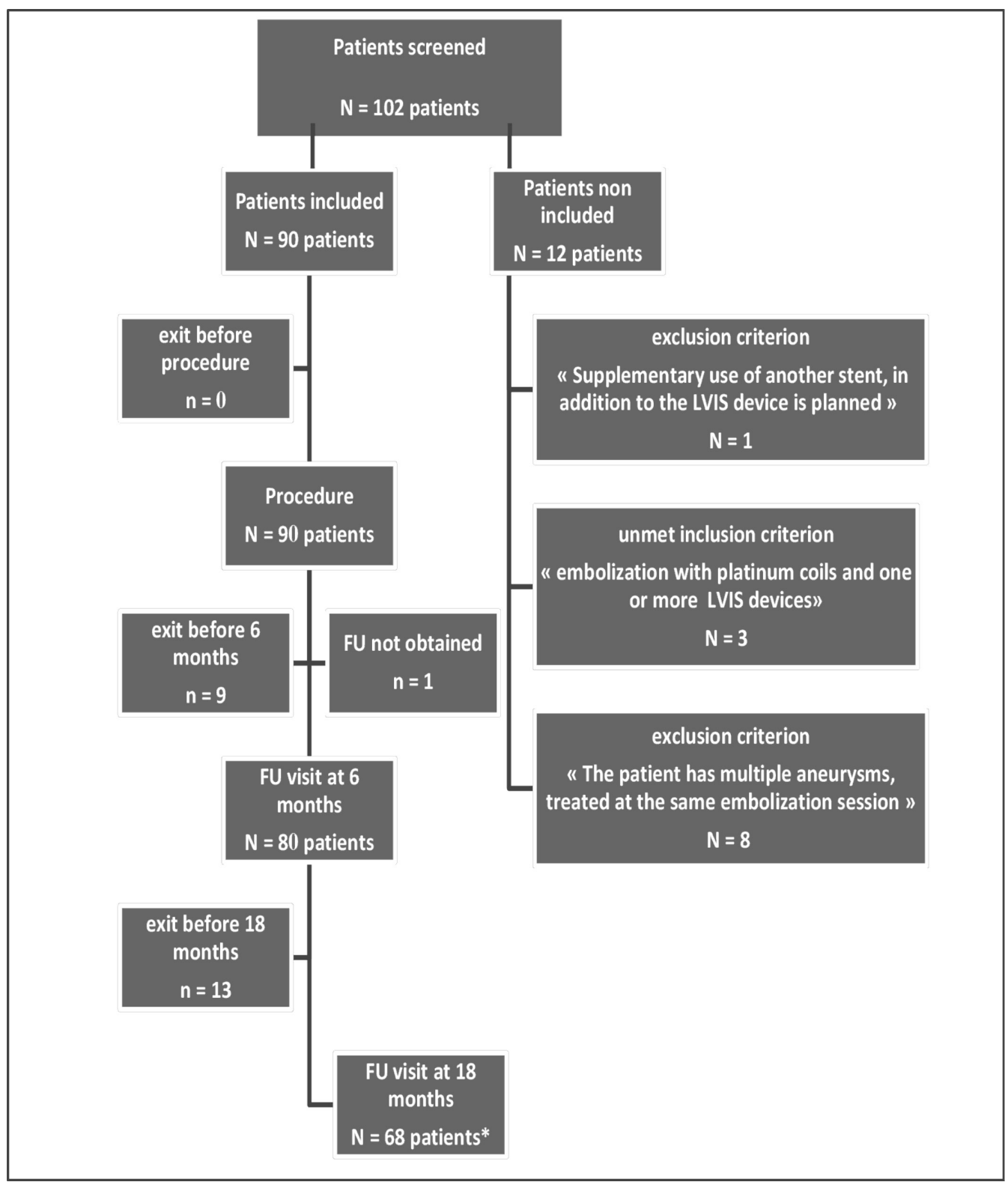

Figure 1 Flowchart of included and analyzed population. Overall, 90 patients were included and analyzed. * One patient had follow-up at 18 months but not at 6 months. 


\section{Outcome measures and statistical analysis}

\section{Performance evaluation criteria}

Anatomic stability was evaluated using several components: device position stability; permeability of the parent artery; degree of aneurysm occlusion; and stability of aneurysm occlusion at 6 months and 18 months.

Percentages were calculated by the modified Wald test. Comparisons between measurements at the end of treatment and those at 6 or 18 months were performed using the McNemar test for paired binary qualitative data, the Wilcoxon signed ranks test for ordinal matched qualitative data, and the Bhapkar test for multimodal qualitative matched data.

Aneurysm occlusion degree and stability were compared at each follow-up time point using the $\chi^{2}$ or Fisher exact tests.

\section{Security evaluation criteria}

Patients' clinical status was assessed with the mRS. The permanent morbidity rate was calculated as the percentage of patients with an adverse event which resulted in a $\mathrm{mRS}>2$ at the time of clinical evaluation (6 and 18 months). Mortality, permanent morbidity, and events with sequelae rates were statistically analyzed by the modified Wald method. Comparisons between the two types of stents (LVIS and LVIS Jr) regarding these security evaluation criteria were performed using the $\chi^{2}$ or Fisher exact tests.

\section{Management of missing data}

Missing data were not replaced and were treated as such on subsequent analyses.

\section{RESULTS}

The database was frozen on 29 April 2015 for analysis. Of the 102 patients screened by the 10 participating centers, 90 were included and analyzed and 12 were not included due to non-compliance with the selection criteria. The details of the unmet selection criteria are shown in the flowchart (figure 1). Of the 22 patients $(22 / 90,24.4 \%)$ who had withdrawn prematurely from the study, 5.6\% (5/90) were deceased, 5.6\% (5/90) withdrew their consent, 6.7\% (6/90) were lost to follow-up, and $6.7 \%(6 / 90)$ exited early for other reasons (mainly because the follow-up was planned for more than 2 years after the procedure). The average follow-up interval of these patients was 9.2 \pm 6.7 months. Six-month and 18-month clinical and imaging outcomes are presented. Baseline patient and aneurysm characteristics are shown in table 1 and endovascular procedure-related data are presented in table 2.

\section{Effectiveness evaluation outcomes}

Seventy-nine imaging follow-ups (51 patients with digital subtraction angiography (DSA) and 28 with MR angiography (MRA)) were analyzed at 6 months by the CoreLab. The imaging data of 66 patients were evaluated at 18 months; two patients were evaluated clinically but did not receive imaging evaluation. The CoreLab attributed the same outcome for each stent in cases of aneurysms treated with more than one stent. The results were attributed to the total number of placed stents (91 stents).

\section{Stent position anatomic stability}

At 6 months, anatomic stability of stent placement was evaluated in $65.8 \%(\mathrm{n}=50)$ of cases by means of comparison of the positions of the radiopaque markers (absence of artifacts); for the remaining $34.2 \%$ of cases, stability was not evaluated due to
Table 1 Baseline characteristics of the patients at inclusion

\begin{tabular}{|ll|}
\hline & Total $\mathrm{n}=90$ patients \\
\hline Age, years, mean \pm SD (median) & $52.68 \pm 10.50(52.50)$ \\
\hline Men, $\mathrm{n}(\%)$ & $38(42.22)$ \\
\hline Medical history, $\mathrm{n}(\%)$ & \\
\hline Smoking & $59(65.56)$ \\
\hline Intracranial ischemic stroke & $12(13.33)$ \\
\hline Intracranial hemorrhagic stroke & $27(30.00)$ \\
\hline Diabetes & $1(1.11)$ \\
\hline Hypertension & $37(41.11)$ \\
\hline Arteriovenous malformations & $1(1.11)$ \\
\hline Peripheral vascular diseases & $2(2.22)$ \\
\hline Cardiovascular disease & $10(11.11)$ \\
\hline Family history of aneurysm & $8(8.89)$ \\
\hline Aneurysm diagnosis, $\mathrm{n}(\%)$ & \\
\hline Incidental finding & $66(73.33)$ \\
\hline Symptomatic & $24(26.67)$ \\
\hline Score WFNS, $\mathrm{n}(\%)$ & \\
\hline 0 & $78(86.67)$ \\
\hline 1 & $11(12.22)$ \\
\hline 2 & $1(1.11)$ \\
\hline Multiple aneurysms, $\mathrm{n}(\%)$ & $27(30.00)$ \\
\hline 2 & $17(18.89)$ \\
\hline 3 & $7(7.78)$ \\
\hline 4 & $2(2.22)$ \\
\hline Treated in the acute phase $(<30$ days post rupture) $\mathrm{n}$ & $1(1.11)$ \\
\hline (\%) & $23(25.56)$ \\
\hline & $4(4.44)$ \\
\hline
\end{tabular}

Not treated in the acute phase ( $>30$ days post rupture),

$\mathrm{n}(\%)$

$18(20.00)$

Missing data

1

Rupture to treatment delay, months, mean $\pm \mathrm{SD}$ (median)

$22.28 \pm 35.74(7.73)$

Aneurysm size (CoreLab data)

Height, mm, mean \pm SD (median)

$5.8 \pm 3.0(5.7)$

Width, $\mathrm{mm}$, mean $\pm \mathrm{SD}$ (median)

$5.8 \pm 2.9(5.0)$

Neck, mm, mean \pm SD (median)

$4.7 \pm 2.0(4.5)$

Dome-to-neck ratio, $\mathrm{n}(\%)$

$<2$

$86(95.56)$

$\geq 2$

$4(4.44)$

Large aneurysms ( $\geq 10 \mathrm{~mm}), \mathrm{n}(\%)$

$9(10.00)$

Small aneurysms $(<10 \mathrm{~mm}), \mathrm{n}(\%)$

$81(90.00)$

Parent artery (CoreLab data)

Distal diameter, $\mathrm{mm}$, mean $\pm \mathrm{SD}$, (median)

$2.4 \pm 0.5(2.4)$

Proximal diameter, $\mathrm{mm}$, mean $\pm \mathrm{SD}$ (median)

$2.8 \pm 0.6(2.6)$

Retreatment of previously treated aneurysm, $n(\%)$

$28(31.11)$

Clip

$2(2.22)$

Coiling

$26(28.89)$

Aneurysm location, $\mathrm{n}(\%)$

Internal carotid artery

$6(6.67)$

Anterior choroidal artery

1 (1.11)

Anterior communicating artery

$32(35.56)$

Posterior communicating artery

1 (1.11)

Superior cerebellar artery

$2(2.22)$

Anterior cerebral artery

1 (1.11)

Middle cerebral artery

33 (36.67)

Posterior cerebral artery

1 (1.11)

Ophthalmic artery

1 (1.11) 


\begin{tabular}{ll}
\hline Table $1 \quad$ Continued & \\
\hline & Total $\mathbf{n}=\mathbf{9 0}$ patients \\
\hline Carotid bifurcation ('T') & $2(2.22)$ \\
\hline Cavernous internal carotid artery & $2(2.22)$ \\
\hline Basilar tip & $3(3.33)$ \\
Basilar artery & $5(5.56)$ \\
\hline
\end{tabular}

artifacts on MRAs. All evaluated stents were stable at 6-month follow-up. Comparative analysis (modified Wald test) of stent position stability at 6 months showed the absence of a statistically significant difference between the stent types (LVIS or LVIS Jr) $(\mathrm{P}=0.74)$.

At 18 -month follow-up, 66 imaging data were reviewed by the CoreLab (54 angiograms and 12 MRIs; 2 imaging data were not reviewed). Evaluation of stent stability by comparison of stent marker position was feasible in $86.2 \%$ of cases $(n=56)$. All of the evaluated stents were stable at 18 months after stenting.

\section{Parent artery patency}

Mean initial diameter of the parent arteries before stent deployment was $2.8 \pm 0.6 \mathrm{~mm}$ (median $2.6 \mathrm{~mm}$ ) proximally and $2.4 \pm 0.5 \mathrm{~mm}$ (median $2.4 \mathrm{~mm}$ ) distally to the stent anchoring zone. CoreLab analysis of the available angiographic data immediately after the procedure and at 6-month follow-up showed patency of the parent artery in $95.4 \%$ and $100.0 \%$ of the evaluated cases (available and artefact-free imaging data), respectively. Eighteen-month controls did not differ from the 6-month controls.

One case of parent artery stenosis was found overall $(1.1 \%$, $1 / 90)$, inferior to $50 \%$ of the normal arterial lumen. Three cases of parent artery occlusion occurred during the procedure. One patient had stent thrombosis without any possibility of arterial recanalization, despite several attempts. The second patient underwent parent artery occlusion during the procedure (manipulation of the stent resulted in dissecting lesion with thrombosis of the right anterior cerebral artery; the stent was not completely deployed and was eventually removed). The third patient had partial in-stent thrombosis, resulting in occlusion of basal ganglia perforators and distal emboli, resulting in hemiplegia. The patient decided to abandon the study and refused imaging follow-up.

The statistical comparison of parent artery diameters (proximal and distal to the anchoring zone) at 6-month imaging follow-up compared with the pre-stenting measurements showed the absence of a statistically significant difference $(\mathrm{P}=1.00$, Wilcoxon rank sum test for paired samples).

\section{Aneurysm occlusion rates}

The total aneurysm occlusion rate was $91.0 \%$ on immediate post-procedure angiograms (95\% CI $83.0 \%$ to $95.6 \%$ ) and remained unchanged at 6-month follow-up (95\% CI $82.3 \%$ to $95.8 \%)$. Comparison of aneurysm occlusion rates at 6 months with the two stent types (LVIS and LVIS Jr) showed no statistically significant difference $(\mathrm{P}=1.00$, Fisher exact test). Aneurysm size (small or large) did not seem to affect the 6-month occlusion rate $(\mathrm{P}=0.07$, Fisher exact test).

At 18 months the complete aneurysm occlusion rate was $92.4 \%$ (95\% CI $83.0 \%$ to $97.1 \%$ ), with no statistically significant difference from the post-procedure results $(\mathrm{P}=1.00)$. The aneurysm occlusion rate at 18 months was independent of the stent type (LVIS and LVIS Jr) $(\mathrm{P}=0.41)$ and aneurysm size $(\mathrm{P}=0.32)$ (table 3).
Table 2 Endovascular procedure-related data

\begin{tabular}{|c|c|}
\hline & $\begin{array}{l}\text { Total } \\
\mathrm{n}=90 \text { patients } / 90 \text { treated } \\
\text { aneurysms } / 104 \text { stents } \\
\text { used/91 stents placed }\end{array}$ \\
\hline Number of aneurysms treated per patient, $\mathrm{n}(\%)$ & $90(100.00)$ \\
\hline 1 & $90(100.00)$ \\
\hline Number of stents used per patient, $\mathrm{n}(\%)$ & $90(100.00)$ \\
\hline 1 & $76(84.44)$ \\
\hline 2 & $14(15.56)$ \\
\hline Number of stents placed per patient, $\mathrm{n}(\%)$ & $90(100.00)$ \\
\hline 0 & $3(3.33)$ \\
\hline 1 & $83(92.22)$ \\
\hline 2 (dual stent/Y-stenting) & $4(4.44)$ \\
\hline $\begin{array}{l}\text { Reasons for non-deployment of stents, n/total stents } \\
\text { used }\end{array}$ & $12 / 104$ \\
\hline Inappropriate selection of stent size & $3 / 104$ \\
\hline Failure of deployment during positionning & $3 / 104$ \\
\hline Technical issues: premature detachment & $2 / 104$ \\
\hline Non-use due to sterility issues & $4 / 104$ \\
\hline Type of stent placed, $n$ (\%) & $91(100.00)$ \\
\hline LVIS & $14(15.38)$ \\
\hline LVIS Jr & $77(84.62)$ \\
\hline Treatment technique, $\mathrm{n}(\%)$ & $90(100.00)$ \\
\hline $\begin{array}{l}\text { Coiling passing through the stent LVIS (trans- } \\
\text { stent) }\end{array}$ & $12(13.33)$ \\
\hline Coiling with the jailing technique & $20(22.22)$ \\
\hline $\begin{array}{l}\text { Coiling and subsequent deployment of the LVIS } \\
\text { stent (post-coiling) }\end{array}$ & $3(3.33)$ \\
\hline Balloon-assisted coiling before LVIS deployment & $47(52.22)$ \\
\hline Y-stenting & $4(4.45)$ \\
\hline Other & $4(4.45)$ \\
\hline Number of used coils, mean \pm SD (median) & $6.40 \pm 3.91(6.00)$ \\
\hline Use of other material, $\mathrm{n}(\%)$ & $90(100.00)$ \\
\hline Distal catheter & $30(33.33)$ \\
\hline Guiding catheter & $90(100.00)$ \\
\hline Catheter with balloon & $53(58.89)$ \\
\hline $\begin{array}{l}\text { Catheter positioning success for deployed stents, } \\
\mathrm{n}(\%)\end{array}$ & $91(100.00)$ \\
\hline $\begin{array}{l}\text { Antiplatelet regimen before endovascular treatment, } \\
\mathrm{n}(\%)\end{array}$ & $90(100.00)$ \\
\hline Acetylsalicylic acid* & $56(62.22)$ \\
\hline Clopidogrel (Plavix) & $72(80.00)$ \\
\hline Prasugrel (Efient) & 15 (16.67) \\
\hline $\begin{array}{l}\text { Antiplatelet regimen during endovascular procedure, } \\
\mathrm{n}(\%)\end{array}$ & $90(100.00)$ \\
\hline Acetylsalicylic acid* & $32(35.56)$ \\
\hline Clopidogrel (Plavix) & $1(1.11)$ \\
\hline Heparin & $62(68.89)$ \\
\hline Abciximab (Reopro) & $2(2.22)$ \\
\hline $\begin{array}{l}\text { Antiplatelet regimen after endovascular treatment, } \\
\mathrm{n}(\%)\end{array}$ & 87 (96.67) \\
\hline Acetylsalicylic acid* & $83(92.22)$ \\
\hline Clopidogrel (Plavix) & 68 (75.56) \\
\hline Prasugrel (Efient) & $14(15.56)$ \\
\hline
\end{tabular}

${ }^{*}$ Aspirin and/or Aspegic and/or Kardegic.

\section{Aneurysm occlusion stability}

At 6 months, imaging data were missing in one of the 80 cases. Stability of the aneurysm occlusion rate at 6-month follow-up compared with the immediate post-procedure angiograms was 
Table 3 (A) Aneurysm occlusion rate as evaluated by the CoreLab immediately post-procedure and at 18-month follow-up. (B) Aneurysm occlusion stability at 18 months (Corelab data) according to the type of the stent as well as the aneurysm size

\begin{tabular}{|c|c|c|c|c|}
\hline \multirow[b]{2}{*}{ (A) Aneurysm occlusion rate } & \multicolumn{2}{|c|}{ Post-procedure ( $n=90$ patients) } & \multicolumn{2}{|c|}{ 18-month follow-up ( $n=68$ patients) } \\
\hline & \multicolumn{4}{|l|}{$P$ value $=1.00$} \\
\hline Missing data & \multicolumn{2}{|l|}{1} & \multicolumn{2}{|l|}{2} \\
\hline Total occlusion, n (\%) $(95 \% \mathrm{CI})$ & \multicolumn{2}{|c|}{81 (91.01) (83.03 to 95.60) } & \multicolumn{2}{|c|}{61 (92.42) (83.08 to 97.10$)$} \\
\hline Residual neck, n (\%) & \multicolumn{2}{|c|}{$8(8.99)(4.40 ; 16.97)$} & \multicolumn{2}{|c|}{$4(6.06)(1.94 ; 15.01)$} \\
\hline \multirow[t]{2}{*}{ Residual aneurysm, n (\%) } & \multicolumn{2}{|l|}{0} & \multicolumn{2}{|c|}{$1(1.52)(0 ; 8.88)$} \\
\hline & \multicolumn{2}{|c|}{ According to type ( $n=91$ stents) $P$ value $=0.41$} & \multicolumn{2}{|c|}{ According to aneurysm size ( $n=90$ aneurysms) $P$ value $=0.32$} \\
\hline (B) Aneurysm occlusion rate at 18 months & LVIS $(n=14)$ & LVIS Jr ( $\mathrm{n}=77)$ & Large $(n=9)$ & Small $(n=81)$ \\
\hline Missing data & 6 & 18 & 4 & 8 \\
\hline Residual aneurysm, n (\%) & 0 & $1(1.69)$ & 0 & $2(2.74)$ \\
\hline Residual neck, n (\%) & 0 & $4(6.78)$ & $1(20.0)$ & $3(4.11)$ \\
\hline Total occlusion, n (\%) & $8(100.00)$ & $54(91.53)$ & $4(80.00)$ & $68(93.15)$ \\
\hline
\end{tabular}

confirmed in $66 / 79$ cases $(83.5 \%, 95 \%$ CI $73.7 \%$ to $89.4 \%)$. In $3 / 79$ cases $(3.8 \%)$ the angiographic result showed improvement (further aneurysm occlusion), in $4 / 79$ cases $(5.1 \%)$ the angiographic follow-up showed recanalization, and in $6 / 79$ cases $(7.6 \%)$ the stability could not be determined from the available imaging data.

The statistical comparison of aneurysm occlusion rates between immediate post-procedure angiograms and 6-month follow-up confirmed the absence of a statistically significant difference $(P=0.43$, Wilcoxon rank sum test for paired samples).

The stability of angiographic control regarding the aneurysm occlusion rate at 18 months compared with the immediate post-procedure result was documented in $92.4 \%$ of cases $(95 \% \mathrm{CI}$ $83.1 \%$ to $97.1 \%)$. In three cases $(4.6 \%)$ a better occlusion rate was observed and in two cases (3.0\%) there was worsening of the aneurysm occlusion rate (table 3 ). Stability of the aneurysm occlusion rate did not depend on the stent type $(\mathrm{P}=1.00)$ or on the size of the treated aneurysm $(\mathrm{P}=1.00)$.

\section{Retreatment at 18 months}

One patient $(1 / 90,1.1 \%, 95 \%$ CI $0 \%$ to $6.6 \%)$ with total aneurysm occlusion immediately post-procedure agreed to retreatment during follow-up due to aneurysm recanalization at 6 months. The patient was retreated between 6 and 18 months by coiling and LVIS Jr stent without adverse event. The angiographic outcome was total occlusion of the aneurysm and patency of the parent artery.

\section{Subgroup analysis}

A posteriori subgroup analysis was performed, independently of the coordinator's statistical analysis, concerning safety outcomes of the different techniques used. This analysis showed no statistically significant difference regarding per-procedure and post-procedure technique-related events. Complex techniques with Y-stent configurations did not show an increase in adverse events compared with the other techniques used in this study. Even though a clear superiority of one technical approach over the others could not be established, a trend towards more technical issues with balloon-assisted coiling followed by stent deployment was found $\left(\chi^{2}\right.$ (trend): $5.348, \mathrm{df}=1, \mathrm{P}=0.02$ ) (see online supplementary table).

\section{Safety assessment results}

Clinical outcome

Clinical outcomes, evaluated with the mRS score, are presented in table 4 . The mRS score did not vary significantly between post-procedure and 6-month clinical follow-up (mean \pm SD $0.01 \pm 0.41$ points). The absence of new neurologic deficit was confirmed at 18-month follow-up compared with the 6-month follow-up.

Procedure- or device-related adverse events with sequelae and permanent morbidity

At 6 months, four procedure-related adverse events with sequelae in four patients $(4.4 \%, 4 / 90)$ were recorded. One patient was evaluated with an mRS score $>2(1.25 \%, 1 / 90)$.

\begin{tabular}{ccll}
\hline Table 4 & Clinical evaluation & & \\
\hline & $\begin{array}{l}\text { Post-procedure } \\
(\mathbf{n}=90 \text { patients) }\end{array}$ & $\begin{array}{l}\text { 6-month follow-up } \\
\text { ( } \mathbf{n}=83 \text { patients) }\end{array}$ & $\begin{array}{l}\text { 18-month follow- } \\
\text { up ( } \mathbf{n}=73 \text { patients) }\end{array}$ \\
\hline mRS score, $\mathrm{n}(\%)$ & & & $\mathrm{MD}=1$ \\
0 & $78(86.67)$ & $72(86.75)$ & $60(83.33)$ \\
1 & $5(5.56)$ & $5(6.02)$ & $6(8.33)$ \\
2 & $4(4.44)$ & $2(2.41)$ & $1(1.39)$ \\
3 & 0 & $1(1.0)$ & 0 \\
4 & $1(1.11)$ & 0 & 0 \\
5 & $2(2.22)$ & 0 & 0 \\
6 & 0 & $3(3.61)$ & $5^{*}(6.94)$ \\
Neurologic deterioration, $\mathrm{n}(\%) \dagger$ & & $\mathrm{MD}=1$ \\
Absent & $83(92.22)$ & $78(97.5)$ & $63(87.50)$ \\
Present & $7(7.78)$ & $5(6.02)$ & $9(12.50)$ \\
Minor & NA & $3(3.61)$ & $6(8.33)$ \\
Moderate & NA & 0 & 0 \\
Severe & NA & $2(2.41)$ & $3(4.17)$ \\
\hline
\end{tabular}

* The five patients evaluated $\mathrm{mRS}=6$ at 18 months are the three patients with $\mathrm{mRS}=6$ at 6 months plus two other patients who died between the 6 -month and 18-month follow-ups and for whom the mRS score was attributed as 6 at 18 months.

†On post-procedure evaluations, neurologic deterioration was determined subjectively by the investigator compared with the clinical status on admission. At 6 and 18-month follow-ups, clinical deterioration was defined as an increase in mRS score compared with the corresponding post-procedure value. $M D$, missing data, NA, not defined. 
At 18 months, the overall permanent morbidity rate was 5/90 $(5.6 \%)$ and the overall adverse events with sequelae related to the stent was $2.2 \%(2 / 90)$.

\section{Mortality}

In the TRAIL study, $5 / 90$ patients $(5.6 \%, 95 \%$ CI $2.1 \%$ to $12.7 \%)$ died during the follow-up period, two during the post-procedure hospitalization period, one between hospitalization and the 6-month follow-up, and two between the 6- and 18-month follow-ups. Only the first three deaths $(3.3 \%, 3 / 90)$ were related to the procedure and the stent, thus representing the procedure-related mortality rate. The other two deaths were unrelated to the procedure and the stent (both patients died due to complications related to metastatic lesions; the first concerned lung metastases and the second brain metastases). There was no statistically significant difference in mortality rates between the type of stent used at 6 months $(\mathrm{P}=0.40$ and $\mathrm{P}=1.00$, respectively) or at 18 months $(\mathrm{P}=0.58$ and $\mathrm{P}=0.66$, respectively).

\section{DISCUSSION}

Low-profile braided stents can be delivered through small-caliber microcatheters and can be resheathed and repositioned for optimal deployment, thus representing an important improvement in the treatment of complex aneurysms in distal locations. ${ }^{8}$ To the best of our knowledge, TRAIL is the first multicenter prospective study to evaluate the safety and effectiveness of the LVIS devices. In accordance with previous multicenter retrospective data, ${ }^{8}$ the study demonstrated excellent angiographic outcomes with a very high rate of total aneurysm occlusion rates and acceptable complication rates. The angiographic follow-up, which is the longest published to date for these devices, showed excellent angiographic stability and absence for the need for retreatment.

Technical feasibility for the LVIS devices in the presented study was $95.2 \%$, which is comparable to the published rates for the Neuroform $(7 \%)^{9}$ and Leo $(5 \%)^{10}$ stents. Four patients (4.4\%) had procedure-related adverse events with sequelae in the 6 months following intervention. The 18 -month permanent morbidity was $5.6 \%$. These outcomes were considered acceptable and comparable to the literature for studies which included both ruptured and unruptured aneurysms. ${ }^{411}$

Even though the 18-month procedure-related mortality rate in the TRAIL study was $3.3 \%$, the overall mortality rate $(5.6 \%)$ was slightly higher than in the ISUIA study. ${ }^{12}$ This is probably related to the limited cohort size, in addition to the fact that, in the TRAIL study, ruptured aneurysms were included.

Immediate total occlusion rates documented in the TRAIL study were clearly higher than the published data for stent-assisted coiling with laser-cut stents. The immediate post-procedure total occlusion rate was $91.0 \%$, which remained unchanged at mid-term and long-term follow-ups $(91.0 \%$ and $92.4 \%$, respectively). Corresponding published data ranged between $42.2 \%$ and $68 \%$ for immediate post-procedure controls and 54-90.8\% at follow-up. ${ }^{1013}$

Similar to other smaller or monocentric studies with the LVIS devices, ${ }^{14} 15$ overall anatomic outcomes were excellent: 100\% of the aneurysms in the study were securely occluded after the procedure (91.0\% total occlusion and $9.0 \%$ residual neck) and remained secure at 6-month and 18 -month imaging follow-up. Only one patient (1.1\%) underwent retreatment during follow-up. In addition, the TRAIL study is the first to publish results at 18 months and showed excellent angiographic stability of the treatments with the LVIS devices.
In accordance with other recent series published for the LVIS and LVIS Jr devices, ${ }^{15-20}$ the present study documented excellent angiographic outcomes in distal intracranial sites. Contrary to other recent reports ${ }^{21}$ with the LVIS Jr devices (8 middle cerebral artery (MCA), 17 anterior communicating artery (Acom), and one pericallosal), no in-stent stenosis was observed with the LVIS Jr stent in the present study (32 Acom and 33 MCA aneurysms). No device oversizing was performed in the TRAIL study. Even though we can only speculate, this discrepancy could probably be attributed to slight oversizing in conjunction with the shape memory properties of the singlewire braided design of the LVIS Jr.

The LVIS design provided easier navigability of the devices, which allowed for their use with double-lumen balloons (Scepter XC; MicroVention, Aliso Viejo, California, USA). The technique of balloon remodeling with subsequent immediate deployment of the stent through the balloon lumen provides support for the deployed coils without the need for exchange maneuvers. This resulted in fewer maneuvers, and thus probably fewer technical complications.

Additionally, the LVIS devices seem to be adapted to complex stenting treatments ${ }^{18} 192122$ such as Y-stenting and coiling for bifurcation aneurysms. The a posteriori subgroup analysis regarding technical issues suggested that Y-stenting was as safe as the other techniques and without technical difficulties, contrary to earlier experiences with relatively higher technical complexity with Y-stenting, mainly due to microcatheter friction. ${ }^{4}$ Even though this analysis was underpowered due to the plethora of treatment strategies resulting in small numbers of cases for subgroup analysis, these results merit further investigation in the future.

Four cases of Y-stenting were included in this study; for this subgroup there were no procedure-related complications, 100\% technical success and $100 \%$ total occlusion rates were obtained, and no technical issues were documented. One of the cases was registered as a technical failure in the database with a single-stent technique; the same aneurysm was subsequently treated with a technically and clinically successful Y-stenting technique, with immediate and 6-month total occlusion outcome. Nevertheless, due to registration-related restrictions, this patient remained in the database as a technical failure and was analyzed as such in the statistical analysis.

The overall experience in this study showed a very promising performance of the devices, especially regarding complex even double-stent techniques, and is in accordance with other studies regarding braided low-profile endovascular stents. ${ }^{23}$ The low-profile braided intracranial stent technology seems to provide neurovascular physicians with an enhanced tool for addressing challenging wide-necked intracranial aneurysms in distal or very tortuous locations. Further imaging data are needed to fully explore the long-term effectiveness of LVIS and LVIS Jr devices. Nevertheless, the initial results are promising in terms of technical feasibility, clinical outcome, and quality of the anatomic result.

\section{Study limitations}

The design of the study was observational and patients were treated according to each site's routine practice. During the 18-month period six patients were lost to follow-up, five patients decided to stop the study, and six other patients had a long-term follow-up of more than 2 years after the procedure.

The low number of patients with a long-term follow-up limits the power of the study; multiple imputation analysis or tipping 
point analysis were not performed. This limitation is often encountered in 'real-life' data collection studies.

\section{CONCLUSION}

In the TRAIL study, the LVIS and LVIS Jr devices have been proved to be safe and effective in the treatment of complex ruptured and unruptured intracranial aneurysms, with very high immediate, mid-term, and long-term total exclusion rates and acceptable morbidity and mortality rates.

\section{Author affiliations}

'Department of Interventional Neuroradiology, CHU-Limoges Dupuytren University Hospital, Limoges, France

${ }^{2}$ Department of Interventional Neuroradiology, Foundation Rothschild Hospital, Limoges, France

${ }^{3}$ Department of Interventional Neuroradiology, CHU Pellegrin, Paris, France

${ }^{4}$ Department of Interventional Neuroradiology, Hôpital Saint-Roch, Nice, France

${ }^{5}$ Department of Interventional Neuroradiology, La Pitié-Salpétrière, Paris, France

${ }^{6}$ Department of Interventional Neuroradiology, Hôpital Bellevue, Saint-Etienne,

France

${ }^{7}$ Department of Interventional Neuroradiology, Hôpital de la Timone, Marseille, France

${ }^{8}$ Department of Interventional Neuroradiology, Hôpital Gui de Chauliac, Montpellier, France

${ }^{9}$ Department of Interventional Neuroradiology, Hôpital Maison Blanche, Reims, France

Contributors The investigators participated in the protocol by performing the cases, giving the necessary clinical and imaging feedback to the corelab and complying with the study's protocol. The investigators have read and approved the submitted manuscript.

Competing interests None declared.

Patient consent Obtained.

Ethics approval National Commission of Information Management and Liberties, France.

Provenance and peer review Not commissioned; externally peer reviewed.

Open access This is an open access article distributed in accordance with the Creative Commons Attribution Non Commercial (CC BY-NC 4.0) license, which permits others to distribute, remix, adapt, build upon this work non-commercially, and license their derivative works on different terms, provided the original work is properly cited and the use is non-commercial. See: http://creativecommons.org/ licenses/by-nc/4.0/

(C) Article author(s) (or their employer(s) unless otherwise stated in the text of the article) 2018. All rights reserved. No commercial use is permitted unless otherwise expressly granted.

\section{REFERENCES}

1 Molyneux AJ, Kerr RS, Yu LM, et al. International Subarachnoid Aneurysm Trial (ISAT) Collaborative Group. International subarachnoid aneurysm trial (ISAT) of neurosurgical clipping versus endovascular coiling in 2143 patients with ruptured intracranial aneurysms: a randomised comparison of effects on survival, dependency, seizures, rebleeding, subgroups, and aneurysm occlusion. Lancet 2005:366:809-17.
2 Ruan $\mathrm{C}$, Long $\mathrm{H}$, Sun $\mathrm{H}$, et al. Endovascular coiling vs. surgical clipping for unruptured intracranial aneurysm: A meta-analysis. Br J Neurosurg 2015;29:485-92.

3 Brinjikji W, Cloft HJ, Kallmes DF. Difficult aneurysms for endovascular treatment: overwide or undertall? AJNR Am J Neuroradiol 2009:30:1513-7.

4 Piotin M, Blanc R, Spelle L, et al. Stent-assisted coiling of intracranial aneurysms: clinical and angiographic results in 216 consecutive aneurysms. Stroke 2010;41:110-5.

5 Wakhloo AK, Mandell J, Gounis MJ, et al. Stent-assisted reconstructive endovascular repair of cranial fusiform atherosclerotic and dissecting aneurysms: long-term clinical and angiographic follow-up. Stroke 2008:39:3288-96.

6 Kono K, Terada T. Hemodynamics of 8 different configurations of stenting for bifurcation aneurysms. AJNR Am J Neuroradiol 2013;34:1980-6.

7 Wanke I, Forsting M. Stents for intracranial wide-necked aneurysms: more than mechanical protection. Neuroradiology 2008;50:991-8

8 Shankar JJS, Quateen A, Weill A, et al. Canadian registry of LVIS Jr for treatment of intracranial aneurysms (CaRLA). J Neurointerv Surg 2017:9:849-53.

9 Lylyk P, Ferrario A, Pasbón B, et al. Buenos Aires experience with the Neuroform self-expanding stent for the treatment of intracranial aneurysms. J Neurosurg 2005:102:235-41.

10 Gross BA, Frerichs KU. Stent usage in the treatment of intracranial aneurysms: past, present and future. J Neurol Neurosurg Psychiatry 2013;84:244-53.

11 Chalouhi N, Jabbour P, Singhal S, et al. Stent-assisted coiling of intracranial aneurysms: predictors of complications, recanalization, and outcome in 508 cases. Stroke 2013:44:1348-53.

12 Wiebers DO, Whisnant JP, Huston J, et al. Unruptured intracranial aneurysms: natural history, clinical outcome, and risks of surgical and endovascular treatment. Lancet 2003;362:103-10

13 Geyik S, Yavuz K, Yurttutan N, et al. Stent-assisted coiling in endovascular treatment of 500 consecutive cerebral aneurysms with long-term follow-up. AJNR Am J Neuroradiol 2013:34:2157-62.

14 Behme D, Weber A, Kowoll A, et al. Low-profile Visualized Intraluminal Support device (LVIS Ir) as a novel tool in the treatment of wide-necked intracranial aneurysms: initia experience in 32 cases. J Neurointerv Surg 2015:7:281-5.

15 Fiorella D, Arthur A, Boulos A, et al. Final results of the US humanitarian device exemption study of the low-profile visualized intraluminal support (LVIS) device. J Neurointerv Surg 2016;8:894-7.

16 Feng Z, Fang Y, Xu Y, et al. The safety and efficacy of low profile visualized intraluminal support (LVIS) stents in assisting coil embolization of intracranial saccular aneurysms: a single center experience. J Neurointerv Surg 2016:8:1192-6.

17 Samaniego EA, Abdo G, Hanel RA, et al. Endovascular treatment of PICA aneurysms with a Low-profile Visualized Intraluminal Support (LVIS Ir) device. J Neurointerv Surg 2016:8:1030-3.

18 Poncyljusz W, Biliński P, Safranow K, et al. The LVIS/LVIS Jr. stents in the treatment of wide-neck intracranial aneurysms: multicentre registry. J Neurointerv Surg 2015; 7:524-9

19 Feng Z, Zhang L, Li Q, et al. Endovascular treatment of wide-neck anterior communicating artery aneurysms using the LVIS Junior stent. J Clin Neurosci 2015:22:1288-91.

20 Feng Z, Li Q, Zhao R, et al. Endovascular treatment of middle cerebral artery aneurysm with the LVIS junior stent. J Stroke Cerebrovasc Dis 2015;24:1357-62

21 Alghamdi F, Mine B, Morais R, et al. Stent-assisted coiling of intracranial aneurysms located on small vessels: midterm results with the LVIS Junior stent in 40 patients with 43 aneurysms. Neuroradiology 2016;58:665-71.

22 Möhlenbruch M, Herweh C, Behrens L, et al. The LVIS Jr. microstent to assist coil embolization of wide-neck intracranial aneurysms: clinical study to assess safety and efficacy. Neuroradiology 2014;56:389-95.

23 Akmangit I, Aydin K, Sencer S, et al. Dual stenting using low-profile LEO baby stents for the endovascular management of challenging intracranial aneurysms. AJNR Am J Neuroradiol 2015:36:323-9. 